\title{
Gestational and lactational exposure to atrazine affects behavior and cognitive functions in Sprague-Dawley rats
}

\author{
Bai Li ${ }^{1}$, Yan Sun ${ }^{1}$, Yanshu Li ${ }^{1}$, Wenbo Jiang ${ }^{1}$, Qilei Chen ${ }^{1}$, Yanping Wu ${ }^{1}$ and Baixiang \\ Li1 \\ ${ }^{1}$ Department of Toxicology, College of Public Health, Harbin Medical University, Harbin, Heilongjiang Province 150081, PR \\ China \\ Correspondence to: Baixiang Li, email: libaix@ems.hrbmu.edu.cn \\ Keywords: atrazine; hippocampus; hypothalamus; behavior; cognitive functions \\ Received: April 04, $2017 \quad$ Accepted: August 26, $2017 \quad$ Published: December 14, 2017 \\ Copyright: Li et al. This is an open-access article distributed under the terms of the Creative Commons Attribution License 3.0 \\ (CC BY 3.0), which permits unrestricted use, distribution, and reproduction in any medium, provided the original author and source \\ are credited.
}

\section{ABSTRACT}

The persistence of atrazine in the environment has been linked to neurodegenerative diseases such as Parkinson's disease and Alzheimer's disease. However, to date, there have been few specialized studies demonstrating the effects of atrazine on behavior, learning, and memory, particularly when exposure occurs during early neurodevelopmental stages. Here, using Sprague-Dawley rats, we investigated neurobehavioral and neurochemical effects associated with high and low doses of maternal atrazine exposure at various gestational and postnatal stages. Results indicated that although maternal weight gain and offspring body and brain weights were not significantly affected by atrazine, behavioral tests (including Morris water maze, shuttle box, step down and tensile tests) showed varying degrees of changes between experimental and control groups. Additionally, using transmission electron microscopy, alterations in the hippocampus and hypothalamus were found within affected offspring. Finally we investigated the effects of maternal atrazine exposure on the CAMP-PKA-CREB signaling pathway, as well as interactions between BAI1 and MDM2 on PSD-95 levels. Results suggested that atrazine exposure during gestation and lactation may affect behavioral and cognitive functions in offspring, and there is likely a gender interaction at different doses. In general, male offspring may be more susceptible to this exposure based on behavioral test observations.

\section{INTRODUCTION}

Atrazine (ATR; 2-chloro-4-ethylamino-6isopropylamino-s-triazine) is a widely used herbicide that is frequently found as a groundwater contaminant and in drinking water $[1,2]$. ATR acts as a photosynthesis inhibitor by inhibiting electron transfer at the reducing site of chloroplast complex II [3]. Furthermore, surveys from America, Italy and Greece have suggested that ATR is one of the top environmental contaminants [4] and affects nervous, reproductive and endocrine systems [510]. Within the central nervous system, a growing body of research suggests that ATR is a dopamine neuronal toxicant and likely plays a role in Parkinson's disease $[5,11,12]$.
Furthermore, ATR has also been reported to alter behavior, learning, cognition and memory functions in humans $[8$, 12-15]. Indeed, Belloni et al. indicated that gestational and postnatal exposure to ATR altered motor activity in juvenile offspring and led to extensive neurodegenerative alterations in the cortex, striatum, hippocampus, and hypothalamus in adulthood $[13,16]$. This suggests that the developing nervous system may be sensitive to ATR, particularly in the early neural developmental stage. Furthermore, studies have indicated that offspring from women who were exposed to ATR during the gestational and lactational periods are affected [17-20].

Recent research has implicated the cyclic adenosine monophosphate-protein kinase A-cAMP response element- 
binding protein (cAMP-PKA-CREB) pathway as a key signaling pathway affecting the formation of cognitive function and memory in animals [20-22]. This G-coupled receptor signaling pathway involves the activation cAMP which activates PKA and leads to the phosphorylation of CREB. This in turn regulates several downstream genes including those encoding for brain derived neurotrophic factor (BDNF) as well as the immediate-early genes $c$-jun and c-fos (Figure 1) [23]. Interestingly, it has been shown that ATR exposure may affect cAMP expression as well as its downstream targets $[24,25]$. We therefore selected the cAMP-PKA-CREB signaling pathway to demonstrate the neurotoxic effects of maternal ATR exposure on the behavior, learning, cognition and memory functions of offspring.

Brain-specific angiogenesis inhibitor 1 (BAI1) was initially thought to be associated with cancerous tumors [26] [27, 28] but has been recently found to regulate spatial learning and synaptic plasticity in the hippocampus [29, 30]. Furthermore, these studies demonstrated that BAI1 may interact with murine double minute 2 (MDM2), a known regulator of postsynaptic density protein-95 (PSD95), which is a protein that has been shown to influence behavior, learning, cognition and memory functions.

We therefore initiated a study to determine whether the cAMP-PKA-CREB signaling pathwayand PSD-95 (as assessed by BAI1 and MDM2 levels) were related to abnormalities found in the offspring of maternal ATR-exposed rats (during pregnancy and lactation). We examined neural developmental abnormalities found in the hippocampus and hypothalamus as well as the associated behavior, learning, cognitive and memory deficits.

\section{RESULTS}

\section{Bodyweight and food consumption}

There were no visible treatment-related changes in bodyweight or food consumption in either the dams or pups after treatment.

\section{Effects of ATR on behavior}

\section{Morris maze test}

Latency times for arrival at the platform in the training stages are shown in Figure 2A. ATR increased the time animals took to reach the platform in both males and females. Times taken to reach the platform were significantly longer in the high-dose groups than in the control group $(\mathrm{p}<0.05)$. In the spatial probe test, targeting times were significantly reduced for males in the highdose group (Figure 2C), but there was no significant change in average speed in either gender (Figure 2B).

\section{Shuttle box test}

The number of conditional reflex responses and mistaken responses are shown in Figure $3 \mathrm{~A}$ and Figure $3 \mathrm{~B}$, respectively. Compared with controls, the number of conditional reflex times decreased significantly in both genders with increasing ATR dosage $(\mathrm{p}<0.05$;

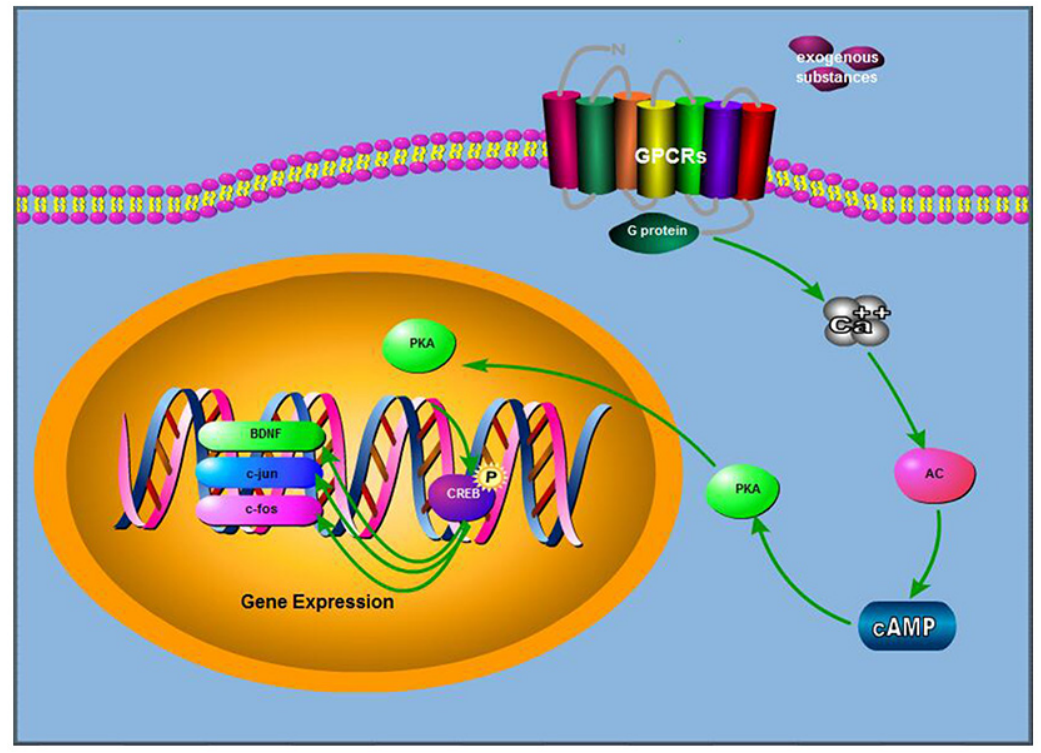

Figure 1: Mechanism of exogenous compounds acting on the signal pathway of the PKA system. Signal molecules act on GPCRs, activate AC and cAMP under the action of $\mathrm{Ca} 2+$, and make PKA active and enter the nucleus. PKA acts on CREB, producing P-CREB, which affects the expression of its downstream genes c-FOS, c-JUN and BDNF. GPCRs: G protein coupled receptors; AC: adenosine cyclase; cAMP: cyclic adenosine monophosphate; PKA: protein kinase A; CREB: cyclic adenosine monophosphate response element binding protein; P-CREB: phosphorylated cyclic adenosine monophosphate response element binding protein; c-JUN: instant inchoate original cancer gene c-JUN; c-FOS: instant inchoate original cancer gene c-FOS; BDNF: brain derived neurotrophic factor. 
Figure 3A) and the number of mistaken responses significantly increased in the high-dose group in both genders ( $p<0.05$; Figure 3B).

\section{Step down test}

The results for memory latency in the ATR-treated groups and controls are shown in Figure 4A. ATR treatment reduced the time taken to return to the bars.
Time taken by male animals to return to the steel bars were significantly shorter in the high-dose group than in the control group $(\mathrm{p}<0.05)$. However, no significant changes were found among the females. Statistical analysis of mistaken responses is shown in Figure 4B. Results indicated that both male and female animals in the high-dose group made significantly more mistakes than in the control group $(\mathrm{p}<0.05)$.

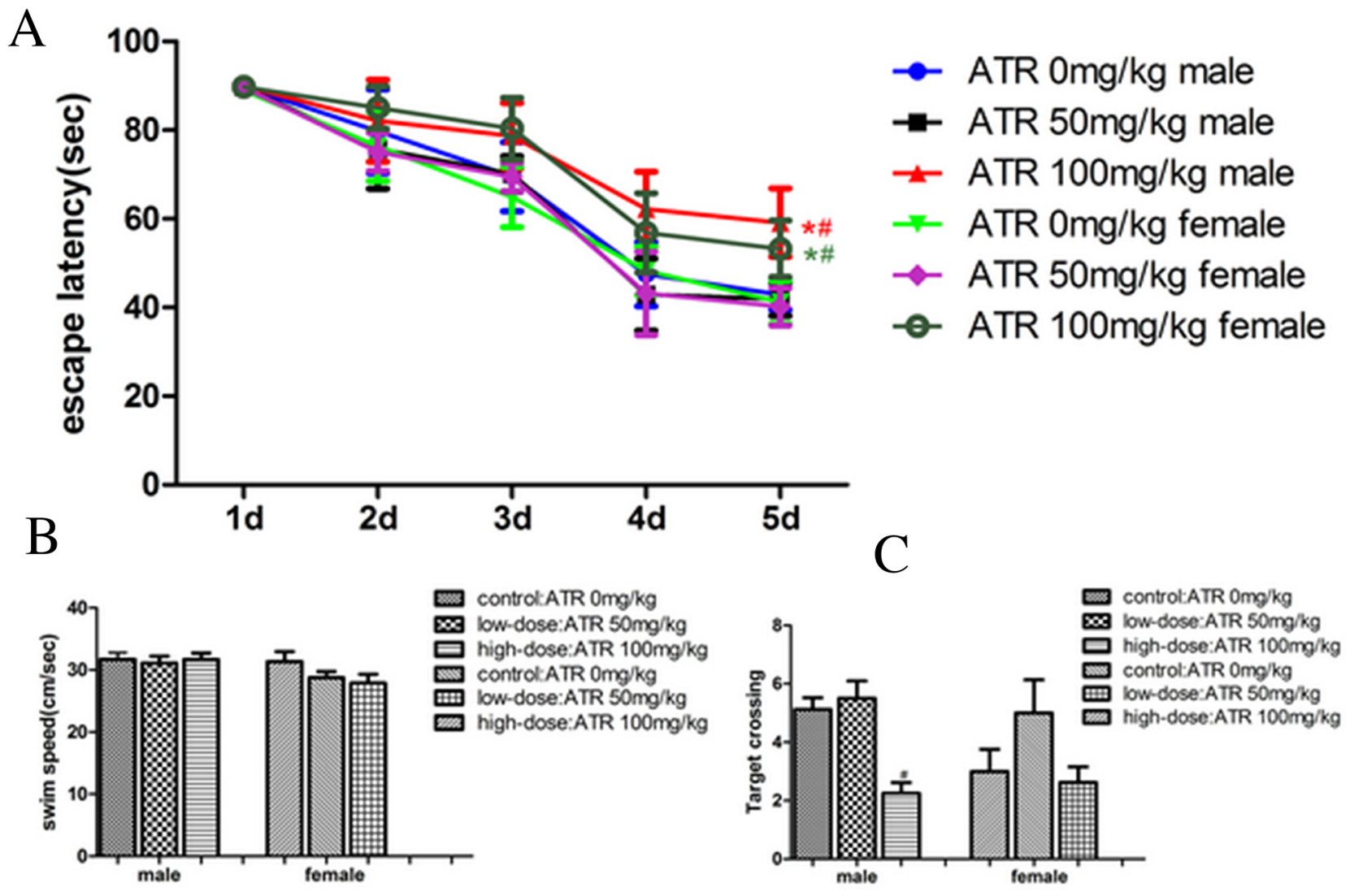

Figure 2: (A) Escape latency of the rats reaching the terrace in the Morris water maze during training trial (B) The times of the rats passing the platform site in the Morris water maze. (C) Average swimming speed of the rats in the Morris water maze. Eight pups per group. Each column represents the mean $\pm \mathrm{SE} ;{ }^{*} \mathrm{p}<0.05$ compared with the control; ${ }^{*}$ significantly different between the low- and high-dose groups.

A

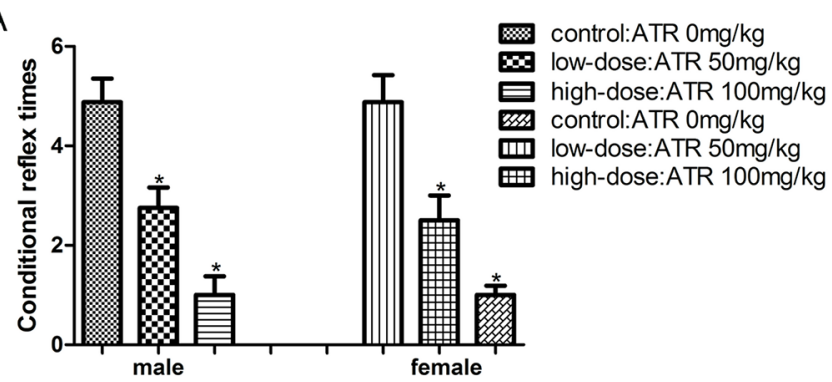

B

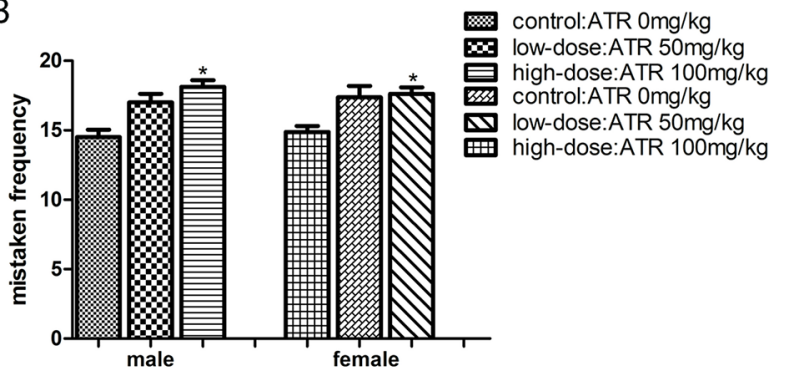

Figure 3: (A) Conditional reflex times of rats in the shuttle-box test. (B) Mistaken frequency of the rats in the shuttle-box test. Eight pups per group. Each column represents the mean $\pm \mathrm{SE} ;{ }^{*} \mathrm{p}<0.05$ compared with the control. 


\section{Effects of ATR on hippocampal and hypothalamic histomorphology}

\section{Optical microscopy}

Histomorphological analysis revealed several minor changes in the hippocampi and hypothalamus of the ATR-treated groups in both genders (Figure 5). In the control group, the pyramidal neurons of the hippocampus showed a hyperchromatic, regular, compact arrangement with a large, round, and conspicuous nucleus in each neuron, while neurons of the hypothalamus were diffused throughout the structure (Figure 5A, 5D). However, in the ATR-treated groups, especially in the high-dose group, the pyramidal neurons of the hippocampus showed a slight change in cell alignment and in some cases, microglial infiltration was present (Figure 5C, 5F).

\section{Electron microscopy}

Electron microscopic observations did not reveal significant changes in the hypothalamus for either gender, but the ultrastructural organization of the hippocampus in both genders was altered in the ATR-treated groups, particulary in the high-dose group (Figure 6). In the control group, neurons had a clear circumference, a smooth bilayer karyolemma, and profuse cytoplasm with chromatin hypodispersion, regular neurofilaments, and neurotubules in both genders (Figure 6A). The neurons contained mitochondria with obvious cristae, clear Golgi apparatuses, and endoplasmic reticulum with ribosomes, and the cells were hypodispersed in the tissue (Figure $6 \mathrm{D})$. In the ATR-treated groups (especially the highdose group), the circumferences and karyolemma of neurons were blurred and shriveled (Figure 6B, 6C). The mitochondria were swollen, with no cristae, the endoplasmic reticulum and Golgi apparatus were flattened with outspread saccules, and the ribosomes had separated from the rough endoplasmic reticulum (Figure 6E, 6F). However, except for some thinning of the postsynaptic membranes, there were no obvious differences in the synapses among the groups (Figure 6G-6I). Unexpectedly, autophagy or a similar phenomenon was present in hippocampal pyramidal cells in males (Figure 6B, 6C, $6 \mathrm{E}, 6 \mathrm{~F})$.

\section{Effects of ATR on mRNA expression}

\section{Differences in dose factor}

The relative expression levels of cAMP, PKA, CREB, BDNF, $c$-jun and $c$-fos are shown in Figure 7I, while the levels of BAI1, MDM2 and PSD-95 are shown in Figure 7II. Within the hippocampus of ATR-treated animals (both genders), expression levels of cAMP mRNA significantly decreased $(\mathrm{p}<0.05)$ with an increase in ATR dose compared to controls. Within the hypothalamus, significant decreases in cAMP mRNA expression were found between the treatment and control groups, but not between females in the low and high dose group $(p<0.05)$, with a similar trend also apparent in males. A significant dose-dependent reduction in PKA mRNA expression was also observed in the ATR-treated groups in the hippocampus of males, although no significant differences were found among the treatment groups in females $(\mathrm{p}<$ 0.05). A similar trend was also found in hypothalamic expression levels, although this decrease was not significant. Interestingly, in the hippocampus, levels of CREB mRNA in the low-dose group were significantly higher than in the control group in both genders, while BDNF mRNA levels were increased in the hypothalamus of males in the low dose group $(\mathrm{p}<0.05)$. Expression of $c$-jun and $c$-fos were significantly reduced in the treatment groups $(\mathrm{p}<0.05)$ compared to controls. However, there were no significant differences in $c$-jun mRNA levels in the hippocampus of males and hypothalamus of females, respectively. Significant decreases were also found in BAI1 and PSD-95 mRNA expression levels in both the hippocampus and hypothalamus of the treated groups compared to controls, particularly in the high-dose group (both genders) ( $\mathrm{p}<0.05)$. Finally, there were no significant changes in MDM2 mRNA expression levels within the hippocampus or hypothalamus of the treated groups compared to controls, although a trend toward decreasing levels was evident.

\section{Differences in gender factor}

In the hippocampus and hypothalamus, mRNA expession of cAMP, CREB, BDNF and $c$-fos showed a significant gender difference $(\mathrm{p}<0.05)$, while PKA and
A

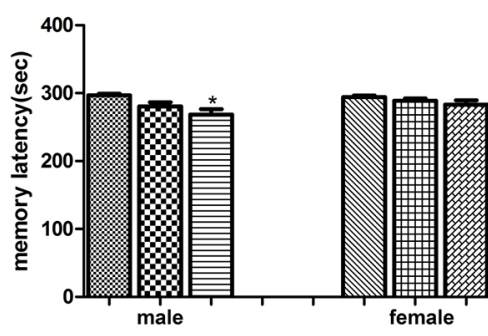

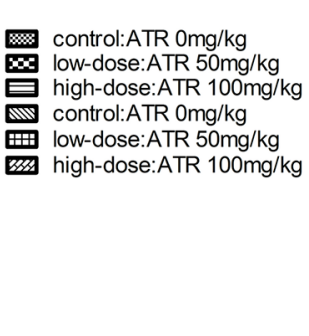

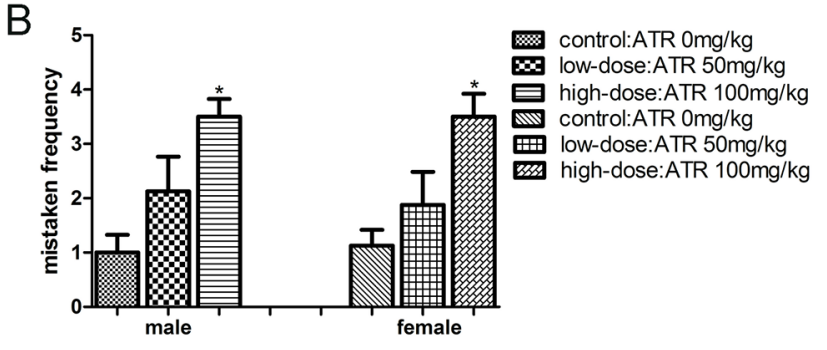

Figure 4: (A) Memory latency of rats in the step-down test. (B) Mistaken frequency of rats in the step-down test. Eight pups per group. Each columns represents the mean $\pm \mathrm{SE} ;{ }^{*} \mathrm{p}<0.05$ compared with the control. 
c-jun mRNA levels showed significant gender differences only in the hypothalamus $(\mathrm{p}<0.05)$. BAI1 mRNA expression levels were significantly different between genders within the hippocampus $(p<0.05)$, while MDM2 and PSD-95 mRNA levels showed no significant differences between genders.

\section{Interaction between dose and gender}

Factorial design results indicated a significant interaction between dose and gender in hippocampal mRNA expression of CREB, BDNF, $c$-jun and BAI1 ( $p$ $<0.05$ ). Moreover, a significant interaction between dose and gender was found in hypothalamic mRNA expression of PKA, CREB, BDNF, $c$-fos and $c$-jun $(\mathrm{p}<0.05)$. No significant interactions were found between either hippocampal or hypothalamic derived MDM2 or PSD-95 mRNA expression.

\section{Effects of ATR on hippocampal and hypothalamic cAMP and BDNF levels}

Levels of cAMP in the hippocampus and hypothalamus (Figure 8) were significantly lower in the ATR-treated groups than in the control groups, particularly in the high-dose groups $(\mathrm{p}<0.05)$. In addition, the reduction in cAMP levels also showed a significant gender difference $(\mathrm{p}<0.05)$. Furthermore, a significant interaction between dose and gender was also found in cAMP levels

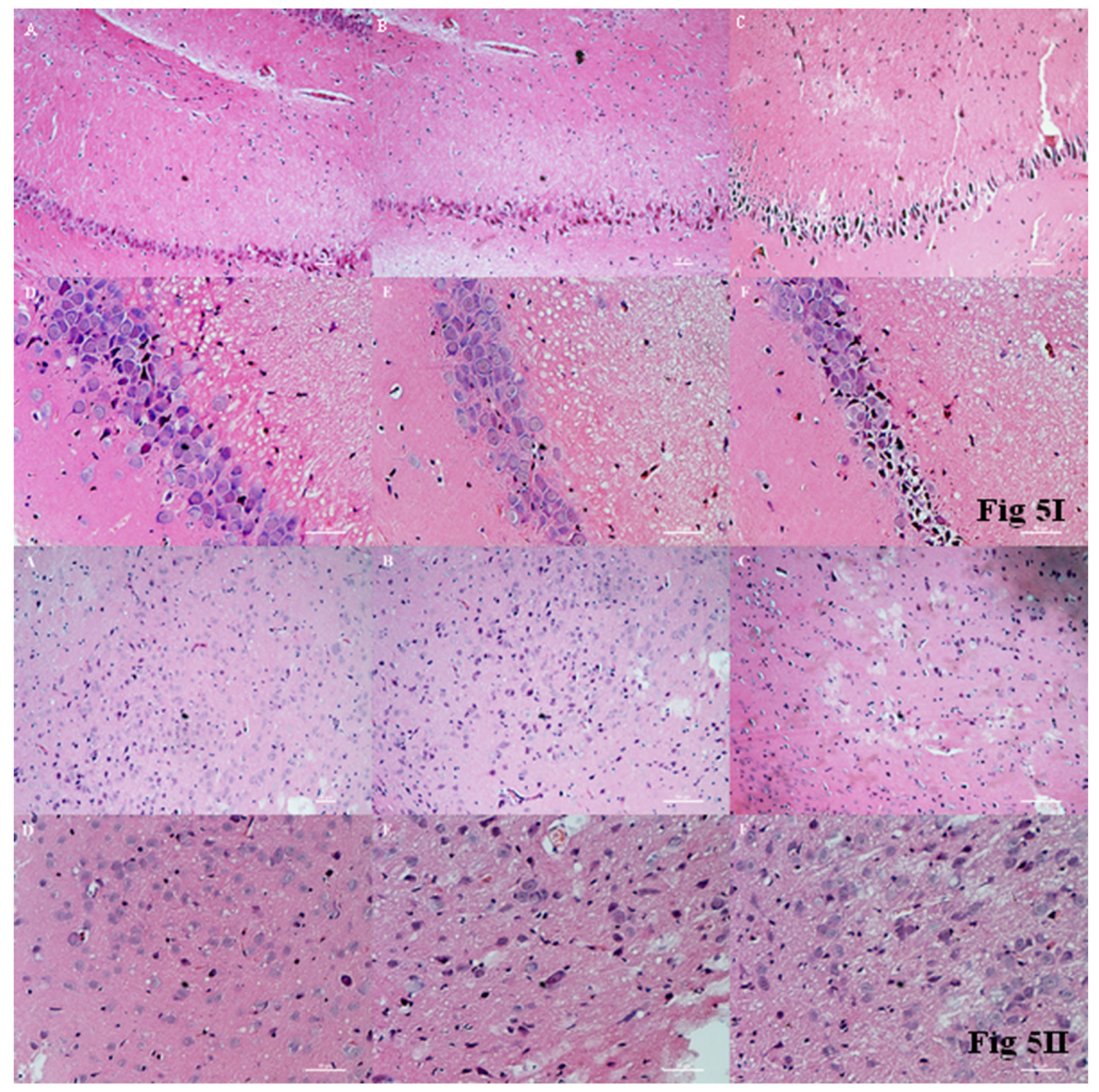

Figure 5: I. Effects of ATR on the morphological changes of the hippocampus under optical microscopy: in the control group: A (10×), $\mathrm{D}(20 \times)$; in the low-dose group: B $(10 \times)$, E (20×); and in the high-dose group: C $(10 \times)$; F $(20 \times)$. II. Effects of ATR on the morphological changes of the hypothalamus under optical microscopy: in the control group: A (10×), D (20×); in the low-dose group: B (10×), E (20×); and in the high-dose group: C $(10 \times)$; F $(20 \times)$. 
in the hypothalamus. The difference in cAMP levels in the hippocampus, however, was not statistically significant. BDNF levels showed a significant dose difference in both the hippocampus and hypothalamus $(\mathrm{p}<0.05)$, and a significant interaction between dose and gender was found in the hippocampus $(\mathrm{p}<0.05)$, but not the hypothalamus.

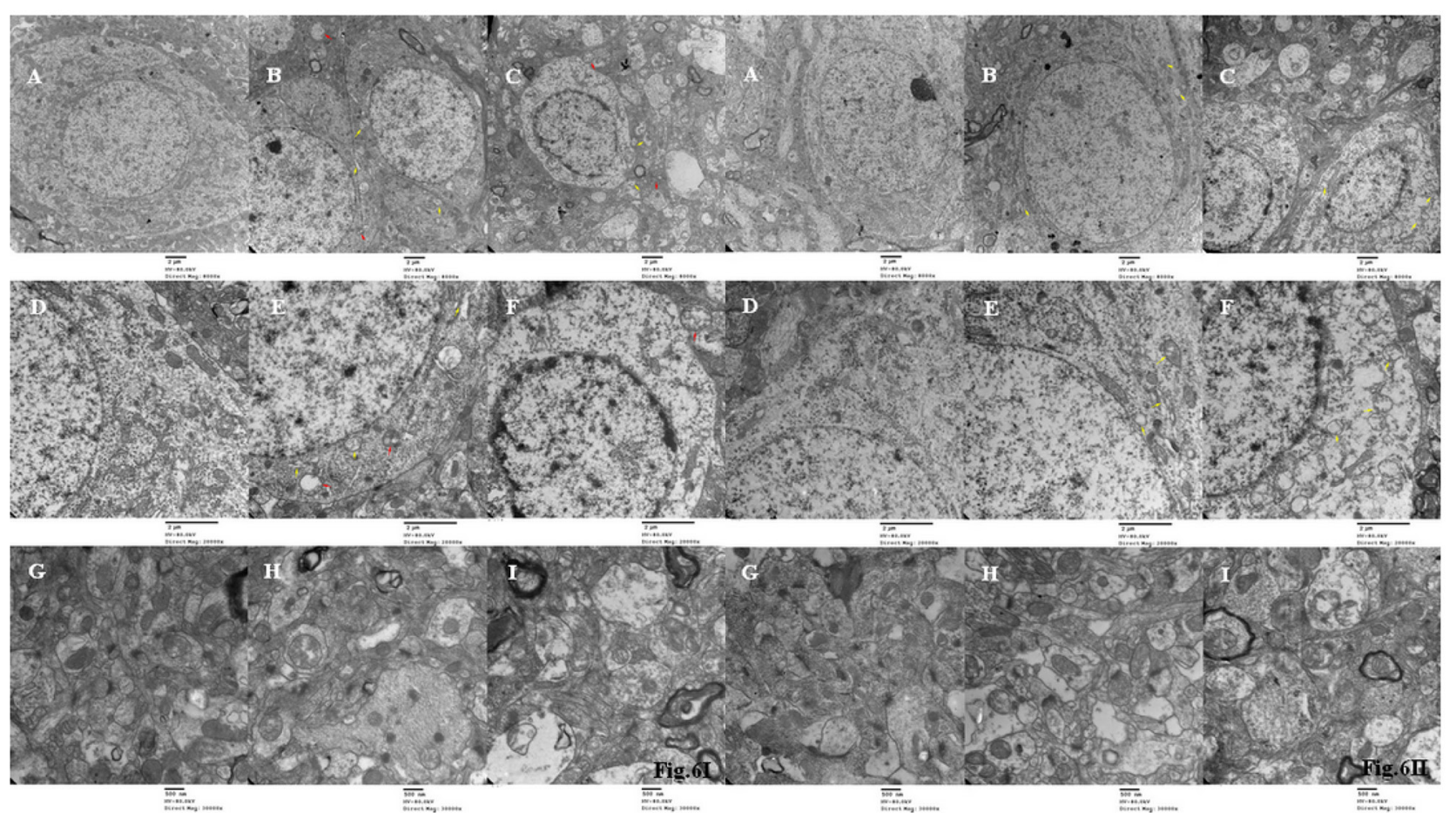

Figure 6: I. Effects of ATR on the microstructure of hippocampal cells of males under electron microscopy: in the control group: A $(8000 \times), \mathrm{D}(20000 \times)$; in the low-dose group: B $(8000 \times), \mathrm{E}(20000 \times)$; and in the high-dose group: C (8000×), F (20000×). II. Effect of ATR on the microstructure of hippocampal cells of females under electron microscopy:in the control group: A ( $8000 \times)$, D (20000×); in the lowdose group: B (8000×), E (20000×); and in the high-dose group: C $(8000 \times)$, F $(20000 \times)$. Effect of ATR on the microstructure of synapses in the hippocampus in males (I) under electron microscopy in the control group: $\mathrm{G}(30000 \times)$; in the low-dose group: $\mathrm{H}(30000 \times)$; and in the high-dose group: I(30000×). Effect of ATR on the microstructure of synapses in the hippocampus in females (II) under electron microscopy in the control group: $\mathrm{G}(30000 \times)$; in the low-dose group: $\mathrm{H}(30000 \times)$; and in the high-dose group: I (30000×). The red arrow: an autophagy or a similar phenomenon; the yellow arrow: a swollen mitochondria or a dilated endoplasmic reticulum.
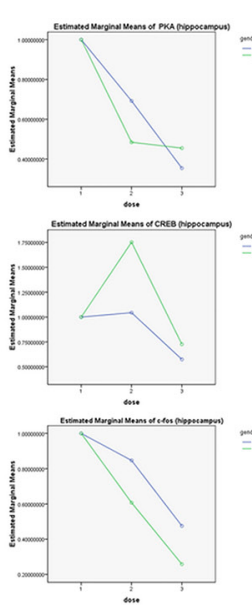
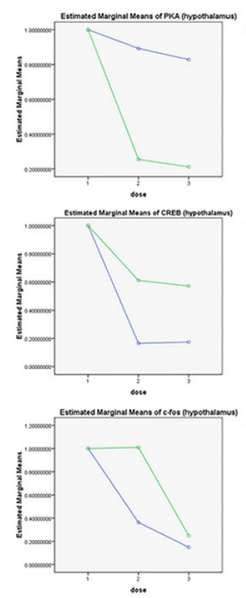
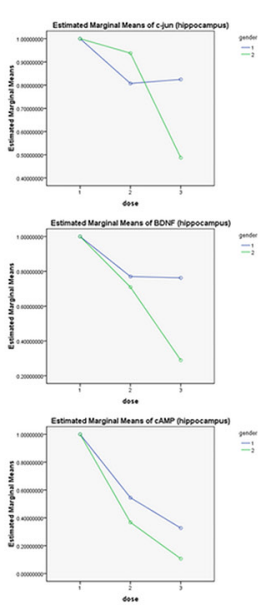
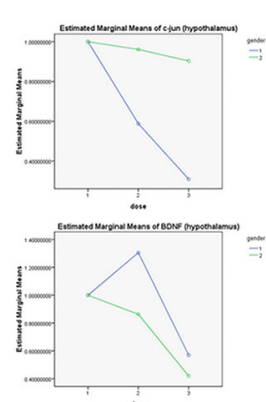

in.

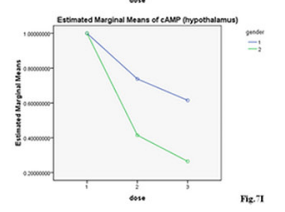

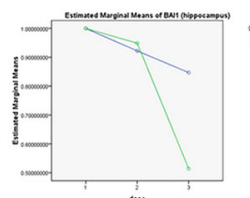
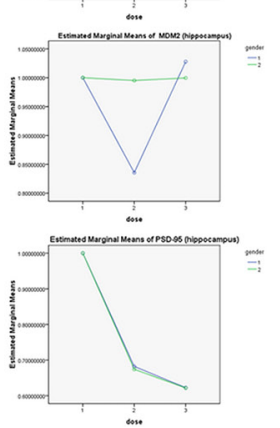
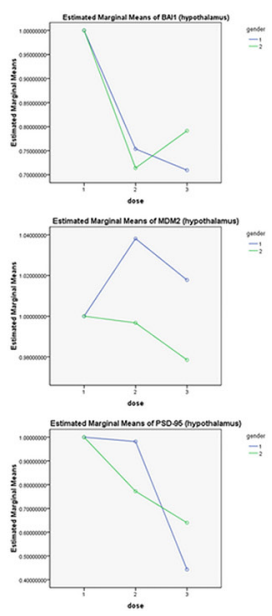

Figure 7: cAMP, PKA, CREB, BDNF, c-jun, c-fos, BAI1, MDM2 and PSD-95 mRNA expression in the hippocampus and hypothalamus of both genders were with RT-PCR (is for cAMP, PKA, CREB, BDNF, c-jun and c-fos; II is for BAI1, MDM2 and PSD-95); 8 pups per group. The blue lines: male; The green lines: female. 


\section{Effects of ATR-treatment on protein expression}

\section{Differences in dose factor}

The effects of ATR-treatment on protein expression were evaluated with western blotting, shown in Figure 9I (PKA, CREB, p-CREB, $c$-jun and $c$-fos) and Figure 9II (BAI1, MDM2 and PSD-95). Statistical analyses are shown in Figure 10I (PKA, CREB, p-CREB, $c$-jun and $c$-fos) and Figure 10II (BAI1, MDM2 and PSD-95). Compared with control groups, there were significant reductions in the expression of PKA (hippocampus of both genders and hypothalamus of females), p-CREB (hipppocampus of males), c-fos (hippocampus of females) and PSD-95 (hippocampus of males) in the ATR-treated groups $(\mathrm{p}<0.05)$. Expression of CREB (hippocampus of males in and hypothalamus of females), p-CREB (both regions in females), $c$-jun (hypothalamus of males and hippocampus of females), $c$-fos (both regions in males and hypothalamus of females), and PSD-95 (hypothalamus of males and both brain regions of females) were also significantly downregulated in the high-dose group ( $\mathrm{p}<$

Estimated Marginal Means of BDNF(hippocampus)

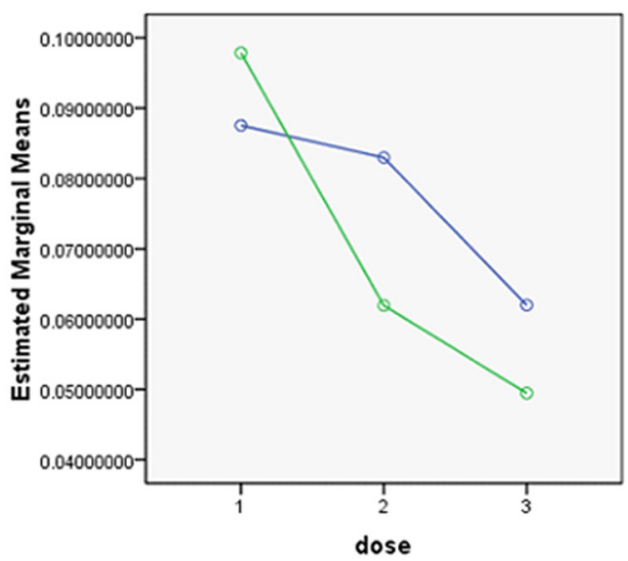

gender

二 1

Estimated Marginal Means of cAMP (hippocampus)

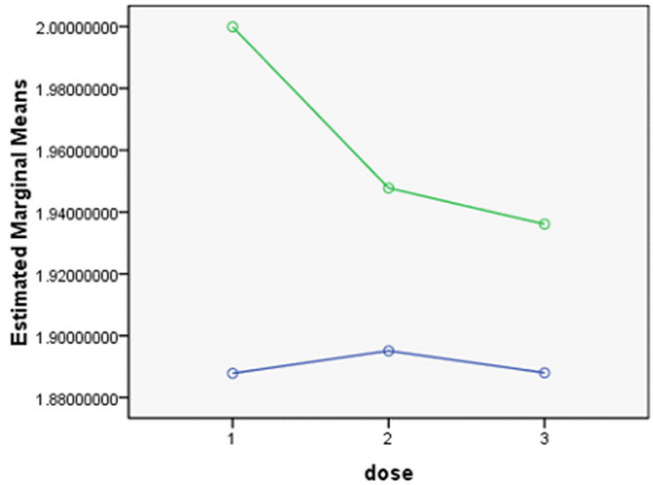

0.05 ), although there were no obvious changes in the lowdose group. No significant differences were observed in the expression of PKA (hypothalamus of males), CREB (hypothalamus of males), p-CREB (hypothalamus of males), $c$-jun (hippocampus of males and hypothalamus of females) or MDM2 (both brain regions in either gender). Of note, although not significant, there was a dosedependent trend toward increasing MDM2 expression. In addition, CREB expression (hippocampus of females) in the low dose group was significantly higher than that of the control group $(p<0.05)$, and in the hypothalamus, BAI1 expression significantly decreased in the low dose group compared to controls $(\mathrm{p}<0.05)$, but increased in the high dose group compared to controls.

\section{Differences in gender}

Statistical analyses indicated that expression of CREB (hippocampus), c-jun (hypothalamus), c-fos (hippocampus), MDM2 (both regions) and PSD-95 (hypothalamus) were significantly different between genders in both the low and high dose groups $(\mathrm{p}<0.05)$.
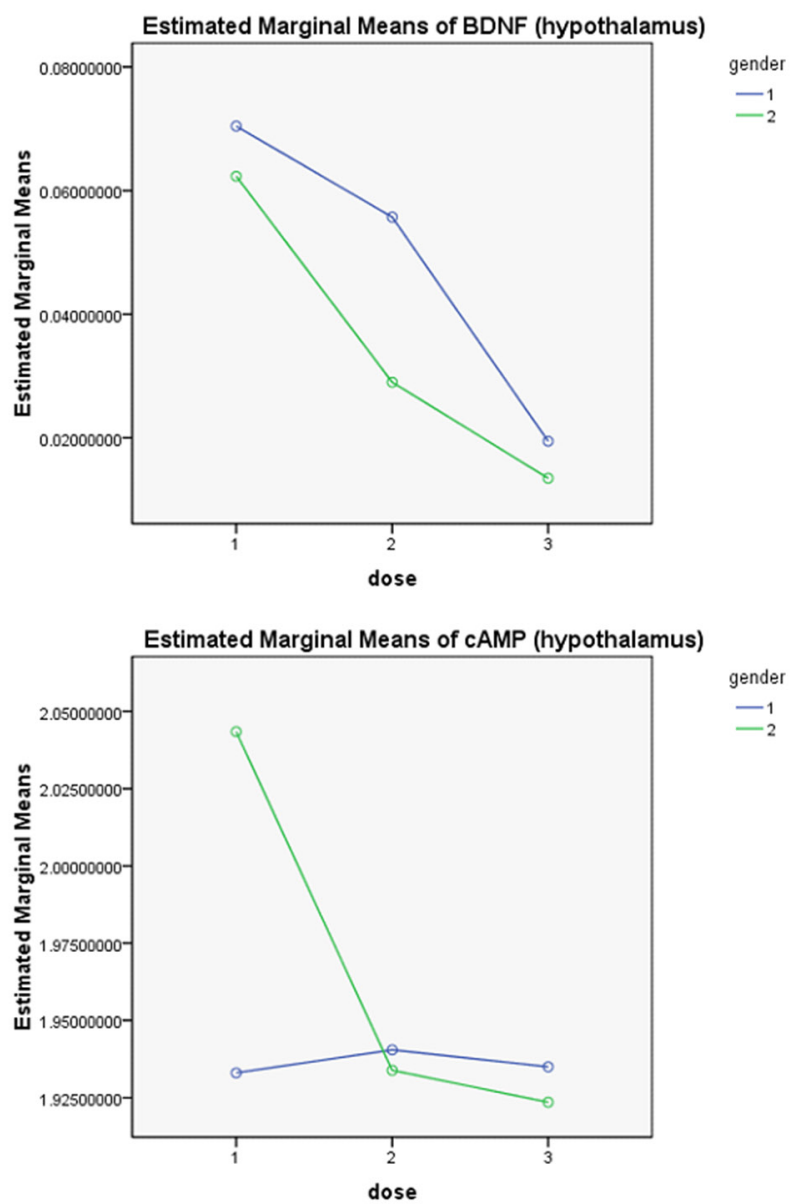

Figure 8: Levels of cAMP and BDNF in the hippocampus and hypothalamus of both genders were determined with ELISA kits; 8 pups per group. The blue lines: male; The green lines: female. 


\section{Interaction between dose and gender}

Factorial design results indicated that there was a significant interaction between dose and gender $(p<0.05)$ in regards to hippocampal CREB expression.

\section{DISCUSSION}

The findings of this study indicated that maternal exposure to ATR during pregnancy and lactation can affect the behavior, learning, cognition and memory of offspring. Furthermore, these adverse effects were likely mediated by a cAMP-PKA-CREB signaling pathwaydependent mechanism as well as a BAI1/MDM2 mediated downregulation of PSD-95 in both the hippocampus and hypothalamus. Moreover, several changes in the expression of the factors examined showed both a gender difference as well as an interaction of dose and gender.

ATR is one of the three N-benzene herbicides which have been shown to have toxic effects on several mammalian functional systems, including the nervous, kinetic and reproductive systems [5, 10, 25, 33, 34], with epidemiological reports indicating a clear danger to humans [19, 35].

The results of the behavioral experiments in this study are in agreement with previous studies [31, 36], whereby the number of conditional reflex times was reduced, and latency was prolonged in both males and females of the ATR-treated groups. This suggests that early maternal exposure to ATR may exert adverse effects on behavior, cognition and memory in offspring.

Optical microscopy showed microglia infiltration in the ATR group, which may associated with an inflammatory reaction. Furthermore, there was no significant difference between the ATR treated group and the control group. Electron microscopy revealed several significant changes in the structure of hippocampal cells observed in the two treatment groups (especially the high dose group). However, in view of the observation that autophagy or the like is present in the pyramidal cells of the hippocampus of the ATR-treated group, we hypothesize that the autophagy seen here is the most likely a direct result of ATR exposure. Additionally, results indicated a significant decrease in the mRNA expression of cAMP, PKA, BDNF, c-jun, c-fos, BAI1 and PSD-95, while protein levels of cAMP, PKA, p-CREB, BDNF, $c$-jun, $c$-fos, BAI1 and PSD-95 were also reduced in both the hippocampus and hypothalamus of the ATR-treated groups. Indeed, most factors tested, with the exception of MDM2, were down regulated with an increasing dose of ATR, regardless of gender or brain region. However, there were exceptions. In particular CREB mRNA expression increased in the low dose group, but was downregulated in the high dose group, while protein levels showed a similar trend but only in the hippocampus of females.
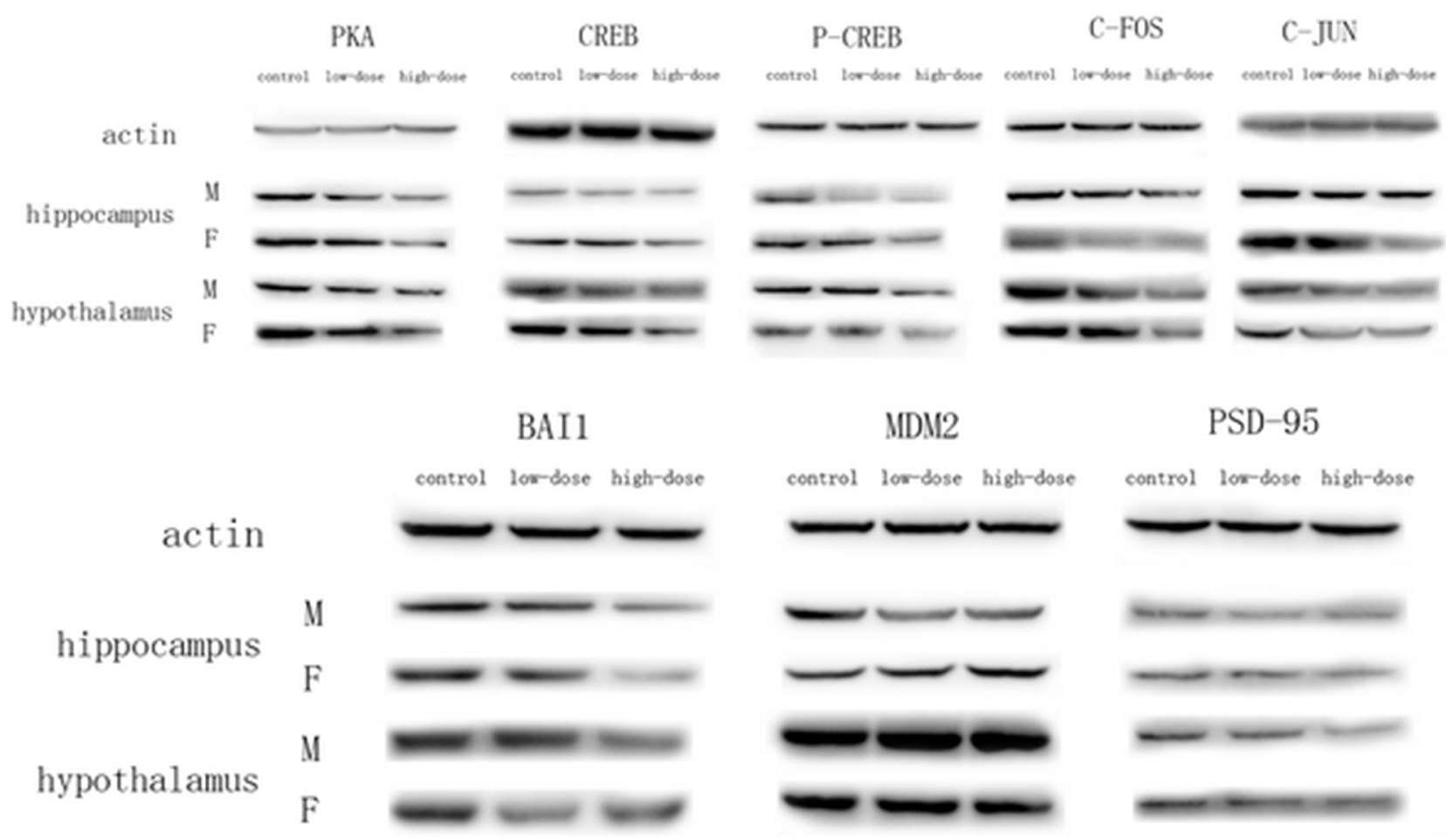

Figure 9: Representative western blots of $\beta$-actin, PKA, CREB, p-CREB, $c$-jun, $c$-fos, BAI1, MDM2 and PSD-95 proteins are shown, together with the pixel densities (I is for PKA, CREB, p-CREB, c-jun and c-fos; II is for BAI1, MDM2 and PSD-95), 8 pups per group. M: Male; F: Female. 
The excitatory effects of ATR may be responsible for this effect and further studies are needed to elucidate the mechanism for this finding. In addition, protein levels of BAI1 in the hypothalamus of females were significantly downregulated in the the low dose group but increased in the high dose group. As estrogen is involved in regulating memory related functions $[37,38]$ we reason that observed changes in the levels of BAI1 within the hypothalamus of females may be due to the regulatory role of hormones, such as estrogen. Additionally, the increased expression of BDNF in the hypothalamus of males in the low dose group may similarly be related to an estrogen-like effect. Finally, the changes found in BAI1 levels in the hypothalamus of male offspring may be due to the fact that ATR has been linked to reproductive and endocrine changes in males and females [39-41], and also has been shown to induce genetic male feminization $[13,30,42]$. Taken together, we hypothesize that early life exposure to ATR may cause feminization in male offspring, resulting in altered levels of hormones. However, the specific hormones that are altered by exposure to ATR, which in turn affects the expression of related genes and proteins, remains to be elucidated. Furthermore, in this study, BAI1 and PSD-95 were significantly downregulated at both the gene and protein level in the ATR-treated groups, while MDM2 showed an increasing trend with increasing dose. These data suggest that the changes in PSD-95 levels may be caused by the interaction of BAI1 and MDM2, which is consistent with previous studies [29, 43]. Furthermore, this lends credit to the idea that BAI1 may not only be related to tumors, but is also an important influencing factor for functional changes in cognitive memory. Additionally, results indicated that early maternal ATR exposure induced changes in the cAMP pathway, which also altered the BAI1 pathway, all of which lends support to previous studies indicating an interconnected role of CREB, BDNF and PSD-95 [44-46].

In conclusion, we have shown that ATR exposure during pregnancy and lactation may have adverse effects related to gene and protein expression in offspring, resulting in alterations in subsequent adult behavior, learning ability, and coginitive and memory functions. These results provide further insight into the neurotoxicity of maternal ATR exposure on offspring and lay the
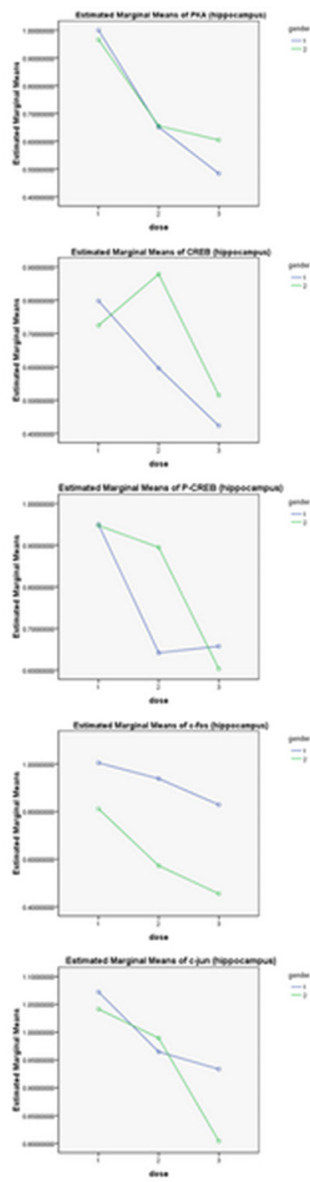
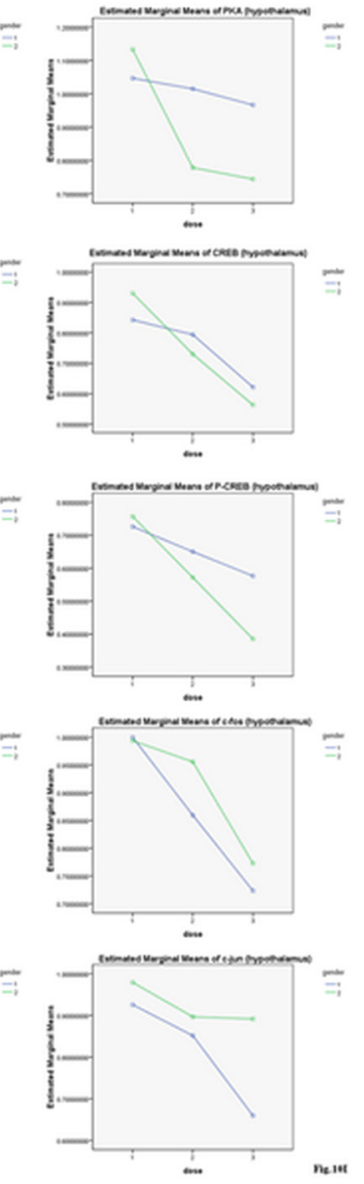
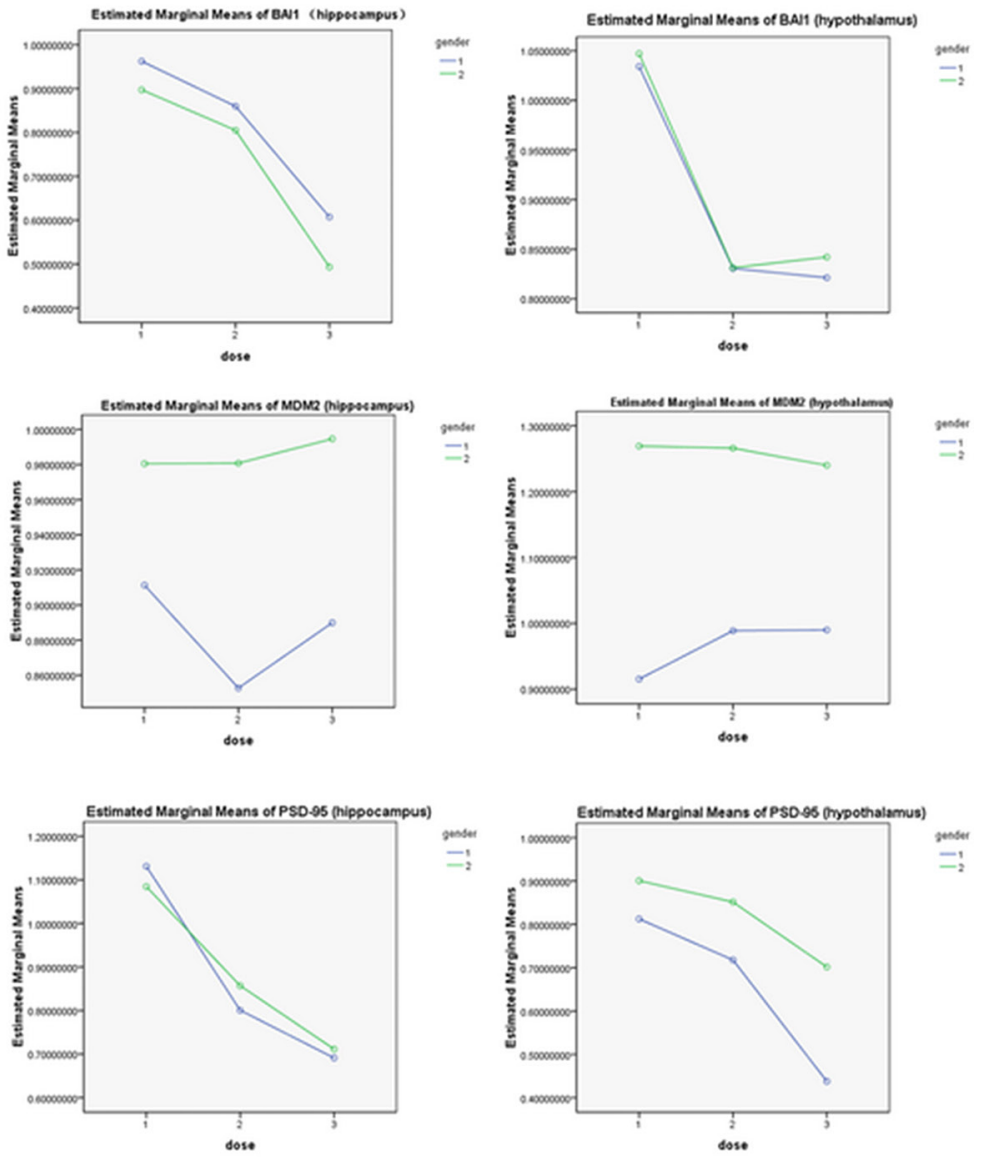

Figure 10: Protein levels of PKA, CREB, p-CREB, $c$-jun, $c$-fos, BAI1, MDM2 and PSD-95 in the hippocampus and hypothalamus of both genders were determined with a western blotting analysis (I is for PKA, CREB, p-CREB, c-jun and c-fos; II is for BAI1, MDM2 and PSD-95); 8 pups per group. The blue lines: male; The green lines: female. 
foundation for future research regarding the role of ATR in the alteration of cognitive functions.

\section{MATERIALS AND METHODS}

\section{Ethics statement}

All the experiments in this study were approved by the Medical Ethics Committee of Harbin Medical University (Harbin, China) and all procedures were carried out in accordance with the National Institutes of Health Standards for Laboratory Animal Research.

\section{Animals, exposure, and tissue collection}

Male and female Sprague Dawley rats (aged 8 weeks, $240 \pm 10 \mathrm{~g}$ ) from Charles River Laboratories (Peking, China) were housed with a $12 \mathrm{~h}$ light/dark cycle at a constant temperature $\left(18-22{ }^{\circ} \mathrm{C}\right)$ and humidity $(40 \%-$ $50 \%)$. Food and water were given ad libitum. The animals were mated, and females were examined the next morning for vaginal plugs. Rats showing plugs were regarded as pregnant and were housed individually. All pregnant rats were randomly divided into three groups (one control group and two treatment groups). The drug doses were selected based on previous research and reports that the oral median lethal dose $\left(\mathrm{LD}_{50}\right)$ of ATR in rats was $>1869$ $\mathrm{mg} / \mathrm{kg}$ (U.S. EPA, 2002) and the lowest observed adverse effect level was $3.5 \mathrm{mg} / \mathrm{kg} / \mathrm{day}$. The rats were administered the drug intragastrically and weighed twice a week (on Monday and Thursday) from gestational day 5 to postnatal day 21 (when all pups were weaned).

At 3 months of age, we chose eight pups from each sex (and each dose) for behavioral tests. Following these tests, animals were sacrificed and brains were removed and rinsed in glassware filled with precooled isotonic $\mathrm{NaCl}$. The hippocampus and hypothalamus were immediately separated, weighed, and snap frozen in liquid nitrogen for subsequent experiments and analyses.

\section{Behavioral tests}

\section{Morris water maze (8 animals in each group)}

The spatial orientation and memory of the pups were evaluated with the Morris maze test. The equipment consisted of a round black tank $(100 \mathrm{~cm}$ in diameter and $58 \mathrm{~cm}$ deep) filled with water (about $42 \mathrm{~cm}$ deep) at a temperature of $20-22{ }^{\circ} \mathrm{C}$. The tank was divided into four equal quadrants. A circular platform $(10 \mathrm{~cm}$ in diameter and $40 \mathrm{~cm}$ high) was installed about $1.5 \mathrm{~cm}$ below the water surface in one of the quadrants. The test was divided into two sections as previously described [31].

Briefly, in the first section (training): the rats were forced to swim four times each day for 5 consecutive days. During each training trial, the animals were put into the water facing the tank wall in one of the four quadrants in a stochastic order each day. The time allowed for the rats to reach the platform was set to $90 \mathrm{~s}$. Rats that failed to find the platform within $90 \mathrm{~s}$ were guided to it with a stick. Each rat was then kept on the platform for $10 \mathrm{~s}$, and the latency and average speed were recorded.

Section two (spatial probe test): on day 6, the platform was removed from the tank and a $90 \mathrm{~s}$ probe test was provided. The times that each animal passed the platform position and the time remaining in the target quadrant were recorded over a period of $90 \mathrm{~s}$.

\section{Shuttle box (8 animals in each group)}

The device consisted of two equal lightproof compartments ( $243 \mathrm{~mm}$ in length, $230 \mathrm{~mm}$ in width and $300 \mathrm{~mm}$ in depth) separated by a plastic sliding door. Stainless steel bars were installed on the floors of the compartments and an electric shock could be given though the bars.

Each session consisted of 20 consecutive cycles per day. The animals were trained for 5 consecutive days and tested on day 6 . Before the experiment, each rat was allowed to adapt to the compartments for $5 \mathrm{~min}$. After adaptation, a cycle began which consisted of a conditioned $10 \mathrm{~s}$ photostimulation. If the animal failed to cross to the opposite compartment, an unconditioned stimulus with a $10 \mathrm{~s}$ electric shock $(0.5-1.0 \mathrm{~mA})$ was given. If the animal crossed to the opposite side during the conditioned stimulus, no electric shock was given. There was a $20 \mathrm{~s}$ intertrial interval between cycles. The numbers of conditioned responses and lack of responses were recorded [32].

\section{Step down test (8 animals in each group)}

The device consisted of eight boxes $(155 \mathrm{~mm}$ in length, $140 \mathrm{~mm}$ in width, and $398 \mathrm{~mm}$ in depth) with stainless steel bars on the bottom and a circular plastic terrace ( $45 \mathrm{~mm}$ in diameter and $45 \mathrm{~mm}$ in height). The animals were trained for 5 consecutive days and tested on day 6 with each rat trained for 5 min per day. Before the training session, the rats were placed on the stainless steel bars in the boxes and after 5 min, an electric shock was given through the bars. The stimulated rats jumped to the terrace to avoid the shock and after stepping down onto the bars were immediately given another electric shock. After $24 \mathrm{~h}$, the animals were placed on the terrace and the time it took to step down was recorded as the "escape latency", an index of short-term memory retention. On day 6 the index was tested to evaluate their long-term memory.

\section{Histomorphology}

\section{Optical microscopy}

Animals were fixed by heart perfusion with chilled physiological saline, immediately followed by $4 \%$ paraformaldehyde in $0.01 \mathrm{M}$ phosphate-buffered saline (PBS; $\mathrm{pH}$ 7.2). The hippocampus and hypothalamus were removed and the samples were then observed with optical microscopy. 


\section{Electron microscopy}

The animals were anesthetized with pentobarbital sodium. The hippocampus and hypothalamus were removed quickly on ice and fixed in chilled $3 \%$ glutaraldehyde. The samples were then observed with electron microscopy.

\section{RNA collection and RT-PCR analysis}

Hippocampal and hypothalamic tissue were dissected out and dissolved in TRIzol reagent. Total RNA was isolated and used to synthesize cDNA with the SYBR Premix Ex Taq II Reagent Kit and gDNA Eraser, according to the manufacturer's instructions (TaKaRa, Japan). To examine the mRNA expression of cAMP, PKA, CREB, BDNF, c-jun, c-fos, BAI1, MDM2 and PSD-95, we used rat-specific primers (Generay, China) as follows: $\beta$-actin (forward: GAGAGGGAAATCGTGCGT; reverse: GGAGGAAGAGGATGCGG; used as an internal control); cAMP (forward: CGCTCACTGTCACT GCTATTG; reverse: CTCGGAACCTCACATACTTGG); PKA (forward: AGGTGACAGACTTCGGTTTTG; reverse: GCTTTGTTGTAGCCTTTGCTC); CREB (forward: ATTGCCCCTGGAGTTGTTAT; reverse: CTGCTTCCCTGTTCTTCATTAG); BDNF (forward: CCAACGAAGAAAACCATAA; reverse: CCAGCAGA AAGAGCAGAG); $c$-jun (forward: ATGGGCACATCA CCACTACA; reverse: TCTGCGGCTCTTCCTTCA); c-fos (forward: GATGTTCTCGGGTTTCAACG; reverse: AGTCGGCTGGGGAATGGTA); BAI1 (forward: TGCC TGAAGAGGAGAAGATGA; reverse: GAGTGAATGGT TGGGGAAGT); MDM2 (forward: GAGGTCTATCGG GTCACAGTCT; reverse: GCCAGTTCTCACGAAG GGT); and PSD-95 (forward: AAGCGGGAATATGAGAT AGACG; reverse: ATAGAGGTGGCTGTTGTACTGG). For PCR analysis, samples were normalized to $\beta$-actin expression by calculating DCT $=\left(\mathrm{CT}_{\text {target }}-\mathrm{CT}_{\beta \text {-actin }}\right), \mathrm{DDCt}$ $=\left(\mathrm{Ct}_{\text {target }}-\mathrm{Ct}_{\beta \text {-actin }}\right)_{\text {treatment }}-\left(\mathrm{Ct}_{\text {target }}-\mathrm{Ct}_{\beta \text {-actin }}\right)_{\text {control }}$, and the $2^{-\triangle \Delta \mathrm{CT}}$ method was used to calculate the relative amounts of the target mRNA.

\section{Enzyme-linked immunosorbent assay (ELISA) for cAMP and BDNF}

The cAMP and BDNF concentrations in hippocampal and hypothalamic tissue were measured using an ELISA kit, according to the manufacturer's instructions (Elabscience Biotechnology Co., China). The plates were sealed and incubated at $37^{\circ} \mathrm{C}$ for $45 \mathrm{~min}$. The ELISA plates were washed three times with wash buffer $(1 \times)$, and horseradish-peroxidase-conjugated fluid $(100 \mu \mathrm{l})$ was added to each well and incubated for $30 \mathrm{~min}$ at 37 ${ }^{\circ} \mathrm{C}$. The plates were then washed five times and substrate reagent $\left(3,3^{\prime}, 5,5^{\prime}\right.$-tetramethylbenzidine) was added to each well and incubated for $15 \mathrm{~min}$ at $37^{\circ} \mathrm{C}$ in the dark. Stop Solution $(50 \mu \mathrm{l})$ was then added to the wells and the
ELISA plates were immediately placed into an Enzyme Mark Instrument. The absorbance was then measured at $450 \mathrm{~nm}$ in a microplate reader (Bio-Tek Elx800, Bio-Tek).

\section{Western blotting analysis}

Hippocampal and hypothalamic tissue samples were rinsed with physiological saline and placed into lysis buffer containing a protease inhibitor and phosphatase inhibitor (Beyotime Biotechnology, China). The mixture was then emulsified with an ultrasonic homogenizer and centrifuged at $10,000 \mathrm{rpm}$ for $10 \mathrm{~min}$ at $4{ }^{\circ} \mathrm{C}$ to remove any contaminants. The protein concentrations in the supernatants were determined with a BCA protein assay kit (Beyotime Biotechnology, China). Each sample (80 $\mu \mathrm{g})$ was separated with SDS-PAGE $(10 \%)$ and then transferred to PVDF membrane. The membranes were blocked with 5\% nonfat milk (dissolved in triphosphate buffered saline with $0.1 \%$ Tween (TBST)) for $45 \mathrm{~min}$ at room temperature and incubated at $4{ }^{\circ} \mathrm{C}$ overnight with either an anti-PKA polyclonal primary antibody (diluted 1:1600 in blocking buffer; Millipore Corporation, MA, USA), anti-CREB polyclonal primary antibody (diluted 1:1000 in blocking buffer; Immuno Way Biotechnology, USA), anti-p-CREB polyclonal primary antibody (diluted 1:1000 in blocking buffer; Immuno Way Biotechnology), anti-c-jun polyclonal primary antibody (diluted 1:800 in blocking buffer; Immuno Way Biotechnology), antic-fos polyclonal primary antibody (diluted 1:800 in blocking buffer; Immuno Way Biotechnology), antiBAI1 polyclonal primary antibody (diluted 1:1000 in blocking buffer; Immuno Way Biotechnology), antiMDM2 polyclonal primary antibody (diluted 1:1000 in blocking buffer; Proteintech Group, USA) or antiPSD-95 polyclonal primary antibody (diluted 1:1500 in blocking buffer; Immuno Way Biotechnology), with anti$\beta$-actin polyclonal antibody (diluted 1:1000 in blocking buffer; Immuno Way Biotechnology) as the control. The membranes were then washed three times in TBST and incubated with horseradish-peroxidase-conjugated goat anti-rabbit $\operatorname{IgG}$ antibody, diluted 1:5000 in blocking buffer; ZSGB-BIO, China) for $1 \mathrm{~h}$ at room temperature. The membranes were washed three times in TBST buffer and the signals detected with the chemiluminiscent ECL Western Blotting Detection Reagent (Beyotime Biotechnology, China). Western blot images were recorded with a chemiluminescence system (Tanon-5200, China) and the quantitative data for all band intensities were measured using Image J v1.50 software.

\section{Statistical analyses}

All values are expressed as means \pm SE. Differences in the escape latency as measured by the Morris water maze test were analyzed with a repeated-measures twoway ANOVA comparison test. We analyzed mRNA expression levels, ELISA data, band intensities, and 
other data with a one-way ANOVA comparison test. Bonferroni's multiple comparison test was used for pairwise comparisons. Factorial design was used to analyze interaction of doses and genders. Differences were considered statistically significant at $\mathrm{p}<0.05$. Statistical analyses were performed with the SPSS 17.0 software.

\section{Abbreviations}

ATR: atrazine;

cAMP: cyclic adenosine monophosphate;

PKA: protein kinase A;

CREB: cAMP response element-binding protein;

P-CREB: phospho- cAMP response element blinding protein

BDNF: brain derived neurotrophic factor;

BAI1: Brain-specific angiogenesis inhibitor 1; MDM2: murine double minute 2;

PSD-95: postsynaptic density protein-95.

\section{Author contributions}

Baixiang Li and Bai Li participated in the research design. Bai Li, Yanping Wu, Wenbo Jiang and

Qilei Chen conducted experiments. Yan Sun and Yanshu Li performed data analysis, and Bai Li wrote or contributed to the writing of the manuscript.

\section{ACKNOWLEDGMENTS}

We are grateful to $\mathrm{Xi} \mathrm{He}$ and Nan Jiang at the Harbin Medical University for editing the manuscript and performing the statistical analysis. This work was supported by the National Nature Science Foundation of China (grant No. 81273109).

\section{CONFLICTS OF INTEREST}

The authors declare that they have no conflicts of interest.

\section{REFERENCES}

1. Gammon DW, Aldous CN, Carr WC Jr, Sanborn JR, Pfeifer KF. A risk assessment of atrazine use in California: human health and ecological aspects. Pest Manag Sci. 2005;61:331-55.

2. Poienaru S, Sarpe N. The residual effect of imazethapyr applied in soybean to barley and winter wheat in Romania. Commun Agric Appl Biol Sci. 2006;71(3 Pt A):829-35.

3. Eldridge JC, Wetzel LT, Stevens JT, Simpkins JW. The mammary tumor response in triazine-treated female rats: a threshold-mediated interaction with strain and speciesspecific reproductive senescence. Steroids. 1999;64:672-8.
4. Guzzella L, Pozzoni F, Giuliano G. Herbicide contamination of surficial groundwater in Northern Italy. Environ Pollut. 2006;142:344-53.

5. Walters JL, Lansdell TA, Lookingland KJ, Baker LE. The effects of gestational and chronic atrazine exposure on motor behaviors and striatal dopamine in male SpragueDawley rats. Toxicol Appl Pharmacol. 2015;289:185-92.

6. Abarikwu SO, Adesiyan AC, Oyeloja TO, Oyeyemi MO, Farombi EO. Changes in sperm characteristics and induction of oxidative stress in the testis and epididymis of experimental rats by a herbicide, atrazine. Arch Environ Contam Toxicol. 2010;58:874-82.

7. Cooper RL, Laws SC, Das PC, Narotsky MG, Goldman JM, Lee Tyrey E, Stoker TE. Atrazine and reproductive function: mode and mechanism of action studies. Birth Defects Res B Dev Reprod Toxicol. 2007;80:98-112.

8. Bardullas U, Giordano M, Rodriguez VM. Chronic atrazine exposure causes disruption of the spontaneous locomotor activity and alters the striatal dopaminergic system of the male Sprague-Dawley rat. Neurotoxicol Teratol. 2011;33:263-72.

9. Rodriguez VM, Thiruchelvam M, Cory-Slechta DA. Sustained exposure to the widely used herbicide atrazine: altered function and loss of neurons in brain monoamine systems. Environ Health Perspect. 2005;113:708-15.

10. Fakhouri WD, Nunez JL, Trail F. Atrazine binds to the growth hormone-releasing hormone receptor and affects growth hormone gene expression. Environ Health Perspect. 2010;118:1400-5.

11. Coban A, Filipov NM. Dopaminergic toxicity associated with oral exposure to the herbicide atrazine in juvenile male C57BL/6 mice. J Neurochem. 2007;100:1177-87.

12. Lin Z, Dodd CA, Xiao S, Krishna S, Ye X, Filipov NM. Gestational and lactational exposure to atrazine via the drinking water causes specific behavioral deficits and selectively alters monoaminergic systems in C57BL/6 mouse dams, juvenile and adult offspring. Toxicol Sci. 2014;141:90-102.

13. Belloni V, Dessi-Fulgheri F, Zaccaroni M, Di Consiglio E, De Angelis G, Testai E, Santochirico M, Alleva E, Santucci D. Early exposure to low doses of atrazine affects behavior in juvenile and adult CD1 mice. Toxicology. 2011;279:19-26.

14. Boulougouris V, Dalley JW, Robbins TW. Effects of orbitofrontal, infralimbic and prelimbic cortical lesions on serial spatial reversal learning in the rat. Behav Brain Res. 2007;179:219-28.

15. Broadbent NJ, Gaskin S, Squire LR, Clark RE. Object recognition memory and the rodent hippocampus. Learn Mem. 2010;17:5-11.

16. Giusi G, Facciolo RM, Canonaco M, Alleva E, Belloni V, Dessi'-Fulgheri F, Santucci D. The endocrine disruptor atrazine accounts for a dimorphic somatostatinergic 
neuronal expression pattern in mice. Toxicol Sci. 2006;89:257-64.

17. Adgate JL, Barr DB, Clayton CA, Eberly LE, Freeman NC, Lioy PJ, Needham LL, Pellizzari ED, Quackenboss JJ, Roy A, Sexton K. Measurement of children's exposure to pesticides: analysis of urinary metabolite levels in a probability-based sample. Environ Health Perspect. 2001;109:583-90.

18. Andrew Clayton C, Pellizzari ED, Whitmore RW, Quackenboss JJ, Adgate J, Sefton K. Distributions, associations, and partial aggregate exposure of pesticides and polynuclear aromatic hydrocarbons in the Minnesota Children's Pesticide Exposure Study (MNCPES). J Expo Anal Environ Epidemiol. 2003;13:100-11.

19. Chevrier C, Limon G, Monfort C, Rouget F, Garlantezec R, Petit C, Durand G, Cordier S. Urinary biomarkers of prenatal atrazine exposure and adverse birth outcomes in the PELAGIE birth cohort. Environ Health Perspect. 2011;119:1034-41.

20. Curwin BD, Hein MJ, Sanderson WT, Striley C, Heederik D, Kromhout H, Reynolds SJ, Alavanja MC. Urinary pesticide concentrations among children, mothers and fathers living in farm and non-farm households in iowa. Ann Olccup Hyg. 2007;51:53-65.

21. Jayachandran R, Liu X, Bosedasgupta S, Muller P, Zhang CL, Moshous D, Studer V, Schneider J, Genoud C, Fossoud C, Gambino F, Khelfaoui M, Müller C, et al. Coronin 1 regulates cognition and behavior through modulation of cAMP/protein kinase A signaling. PLoS Biol. 2014; 12:e1001820.

22. Takeo S, Niimura M, Miyake-Takagi K, Nagakura A, Fukatsu T, Ando T, Takagi N, Tanonaka K, Hara J. A possible mechanism for improvement by a cognitionenhancer nefiracetam of spatial memory function and cAMP-mediated signal transduction system in sustained cerebral ischaemia in rats. $\mathrm{Br} \mathrm{J}$ Pharmacol. 2003;138:642-54.

23. Li B, He X, Sun Y, Li B. Developmental exposure to paraquat and maneb can impair cognition, learning and memory in Sprague-Dawley rats. Mol Biosyst. 2016;12:3088-97.

24. Abarikwu SO, Farombi EO, Kashyap MP, Pant AB. Kolaviron protects apoptotic cell death in PC12 cells exposed to atrazine. Free Radic Res. 2011;45:1061-73.

25. Fan W, Yanase T, Morinaga H, Gondo S, Okabe T, Nomura M, Komatsu T, Morohashi K, Hayes TB, Takayanagi R, Nawata H. Atrazine-induced aromatase expression is SF-1 dependent: implications for endocrine disruption in wildlife and reproductive cancers in humans. Environ Health Perspect. 2007;115:720-7.

26. Kudo S, Konda R, Obara W, Kudo D, Tani K, Nakamura Y, Fujioka T. Inhibition of tumor growth through suppression of angiogenesis by brain-specific angiogenesis inhibitor 1 gene transfer in murine renal cell carcinoma. Oncol Rep. 2007;18:785-91.

27. Zhu D, Hunter SB, Vertino PM, Van Meir EG. Overexpression of MBD2 in glioblastoma maintains epigenetic silencing and inhibits the antiangiogenic function of the tumor suppressor gene BAI1. Cancer Res. 2011;71:5859-70.

28. Kang X, Xiao X, Harata M, Bai Y, Nakazaki Y, Soda Y, Kurita R, Tanaka T, Komine F, Izawa K, Kunisaki R, Setoyama M, Nishimori H, et al. Antiangiogenic activity of BAI1 in vivo: implications for gene therapy of human glioblastomas. Cancer Gene Ther. 2006;13:385-92.

29. Zhu D, Li C, Swanson AM, Villalba RM, Guo J, Zhang Z, et al. BAI1 regulates spatial learning and synaptic plasticity in the hippocampus. J Clin Invest. 2015;125:1497-508.

30. Zhu D, Van Meir EG. BAI1: from cancer to neurological disease. Oncotarget. 2016;7:17288-9. https://doi. org/10.18632/oncotarget.8193.

31. Zhang X, Wang M, Gao S, Ren R, Zheng J, Zhang Y. Atrazine-induced apoptosis of splenocytes in BALB/C mice. BMC Med. 2011;9:117.

32. Langlois VS, Carew AC, Pauli BD, Wade MG, Cooke GM, Trudeau VL. Low levels of the herbicide atrazine alter sex ratios and reduce metamorphic success in Rana pipiens tadpoles raised in outdoor mesocosms. Environ Health Perspect. 2010;118:552-7.

33. Saldana TM, Basso O, Hoppin JA, Baird DD, Knott C, Blair A, Alavanja MC, Sandler DP. Pesticide exposure and selfreported gestational diabetes mellitus in the Agricultural Health Study. Diabetes Care. 2007;30:529-34.

34. Chen Q, Niu Y, Zhang R, Guo H, Gao Y, Li Y, Liu R. The toxic influence of paraquat on hippocampus of mice: involvement of oxidative stress. Neurotoxicology. 2010;31:310-6.

35. Nobakht M, Hoseini SM, Mortazavi P, Sohrabi I, Esmailzade B, Rahbar Rooshandel N, Omidzahir S. Neuropathological changes in brain cortex and hippocampus in a rat model of Alzheimer's disease. Iran Biomed J. 2011;15:51-8.

36. Yamada J, Hatabe J, Tankyo K, Jinno S. Cell type- and region-specific enhancement of adult hippocampal neurogenesis by daidzein in middle-aged female mice. Neuropharmacology. 2016.

37. Gonzalez-Castillo C, Ortuno-Sahagun D, Guzman-Brambila C, Marquez-Aguirre AL, Raisman-Vozari R, Pallas M, Rojas-Mayorquín AE. The absence of pleiotrophin modulates gene expression in the hippocampus in vivo and in cerebellar granule cells in vitro. Mol Cell Neurosci. 2016;75:113-21.

38. Gely-Pernot A, Hao C, Becker E, Stuparevic I, Kervarrec C, Chalmel F, Primig M, Jégou B, Smagulova F. The epigenetic processes of meiosis in male mice are broadly 
affected by the widely used herbicide atrazine. BMC Genomics. 2015;16:885.

39. Hayes TB, Khoury V, Narayan A, Nazir M, Park A, Brown T, Adame L, Chan E, Buchholz D, Stueve T, Gallipeau S. Atrazine induces complete feminization and chemical castration in male African clawed frogs (Xenopus laevis). Proc Natl Acad Sci U S A. 2010;107:4612-7.

40. Pogrmic-Majkic K, Fa S, Samardzija D, Hrubik J, Kaisarevic S, Ph NA. Atrazine activates multiple signaling pathways enhancing the rapid hCG-induced androgenesis in rat Leydig cells. Toxicology. 2016.

41. Hayes TB, Anderson LL, Beasley VR, de Solla SR, Iguchi $\mathrm{T}$, Ingraham $\mathrm{H}$, Kestemont $\mathrm{P}$, Kniewald $\mathrm{J}$, Kniewald Z, Langlois VS, Luque EH, McCoy KA, Muñoz-de-Toro M, et al. Demasculinization and feminization of male gonads by atrazine: consistent effects across vertebrate classes. J Steroid Biochem Mol Biol. 2011;127:64-73.
42. Hayes T, Haston K, Tsui M, Hoang A, Haeffele C, Vonk A. Herbicides: feminization of male frogs in the wild. Nature. 2002;419:895-6.

43. Hu X, Ballo L, Pietila L, Viesselmann C, Ballweg J, Lumbard D, Stevenson M, Merriam E, Dent EW. BDNF-induced increase of PSD-95 in dendritic spines requires dynamic microtubule invasions. J Neurosci. 2011;31:15597-603.

44. Hallenborg P, Feddersen S, Francoz S, Murano I, Sundekilde U, Petersen RK, Akimov V, Olson MV, Lozano G, Cinti S, Gjertsen BT, Madsen L, Marine JC, et al. Mdm2 controls CREB-dependent transactivation and initiation of adipocyte differentiation. Cell Death Diff. 2012;19:1381-9.

45. Jin Y, Zeng SX, Lee H, Lu H. MDM2 mediates p300/ CREB-binding protein-associated factor ubiquitination and degradation. J Biol Chem. 2004;279:20035-43.

46. Kihara T, Surjono TW, Sakamoto M, Matsuo T, Yasuda Y, Tanimura T. Effects of prenatal rubratoxin-B exposure on behaviors of mouse offspring. Toxicol Sci. 2001;61:368-73. 